\title{
OS MECANISMOS DE CONTROLE NACIONAIS E INTERNACIONAIS QUE INFLUENCIARAM E INFLUENCIAM A EDUCAÇÃO BRASILEIRA
}

\author{
THE NATIONAL AND INTERNATIONAL CONTROL MECHANISMS
}

THAT INFLUENCED AND INFLUENCE BRAZILIAN EDUCATION

\author{
Edite Maria Sudbrack ${ }^{1}$ \\ Silvia Regina de Oliveira ${ }^{2}$ \\ Elke Luanne da Silva Xavier ${ }^{3}$
}

\section{RESUMO}

Este estudo foi embasado na pesquisa documental e bibliográfica, mediante leitura crítica de obras, artigos científicos e documentos. O Brasil, assim como muitos outros países, é influenciado pelas ações da Organização para Cooperação e Desenvolvimento Econômico (OCDE), que vem direcionando, sobretudo, a principal avaliação de larga escala que é desenvolvida atualmente no país, o Índice de Desenvolvimento da Educação Básica (IDEB). A reforma do Estado, proposta na década de 1990, vem delineando as políticas educacionais no Brasil, na medida em que propõe a avaliação externa como mecanismo de controle e regulação do Estado. Neste artigo, faremos reflexões sobre a Nova Gestão Pública, Gerencialismo e o Novo Gerencialismo, além de dois eventos educacionais internacionais: a Agenda 2030 e o Fórum Mundial da Educação ocorrido em maio de 2015 na Coréia do Sul. Acreditamos que diante da dinâmica apresentada, o direito educativo colabora para que outros direitos sejam garantidos, e que, a emancipação e mediação são importantes aliadas para a melhoria da qualidade da educação.

Palavras-chaves: Educação; Políticas Públicas; Avaliações de Larga Escala; Gestão Pública.

\begin{abstract}
This study was based on documentary and bibliographic research through critical analysis of publications, scientific articles, and documents. Like many other countries, Brazil is influenced by the Organization for Economic Cooperation and Development (OECD). OECD has been directing, above all, the primary large-scale assessment currently being implemented in the country, the Basic Education Development Index (IDEB). The State
\end{abstract}

\footnotetext{
${ }^{1}$ Atualmente é Pró-reitora de Ensino da Universidade Regional Integrada do Alto Uruguai e da Missões (URI). Pós-Doutorado em Educação (2020) pela Universidade de Aveiro/Portugal; Pós-Doutorado em Educação (2016) pela UFRGS (Universidade Federal do Rio Grande do Sul). Doutora (2002) e Mestre em Educação (1995) pela UFRGS. e-mail: sudbrack@uri.edu.br

${ }^{2}$ Atualmente é mestranda em Educação pelo Programa de Pós-graduação em Educação da Universidade Regional Integrada do Alto Uruguai e da Missões (URI) Campus de Frederico Westphalen/RS. e-mail: silviajna@gmail.com

${ }^{3}$ Atualmente é mestranda em Educação pelo Programa de Pós-graduação em Educação da Universidade Regional Integrada do Alto Uruguai e da Missões (URI) Campus de Frederico Westphalen/RS. e-mail: a097497@uri.edu.br
} 
reform, proposed in the 1990s, has been delineating educational policies in Brazil, as it requests external evaluation as a State control and regulation mechanism. In this article, we will reflect on New Public Management, Managerialism, and New Managerialism, in addition to two international educational events: the 2030 Agenda and the World Education Forum held in May 2015 in South Korea. Given this scenario, we believe that the educational law collaborates so that other rights are guaranteed, and that emancipation and mediation are essential allies for improving the quality of education.

Keywords: Education; Public Policies; Large Scale Assessments; Public Management.

\section{INTRODUÇÃO}

O direito à educação, juridicamente, é reconhecido no cenário internacional, tendo como principal marco, no contexto contemporâneo, a Declaração Universal dos Direitos Humanos, que, em seus trinta artigos, registra os direitos considerados humanos, dentre eles, o educacional.

O documento proclama a educação como um instrumento promotor de conquistas progressivas, comuns para todos os povos e nações, portanto, deve ser protegido pelo ordenamento tanto de âmbito nacional, quanto internacional (SOUZA; KERBAUY, 2018).

O Brasil, assim como outros países da América do Sul, tem sido signatário em diversos eventos internacionais, como por exemplo, os eventos de Jomtien (1990), Dakar (2000) e Incheon (2015).

Organismos internacionais como o Program for Internacional Student Assessment PISA e a Organização das Nações Unidas para Educação, Ciência e Cultura (UNESCO), vêm ganhando espaços de influência em vários setores no território brasileiro, sobretudo na educação.

Novos modelos de gestão e políticas educacionais são percebidos: A Nova Gestão Pública/Novo Gerencialismo deveriam dar respostas as tensões que surgiram após os movimentos sociais buscarem participar das decisões que eram tomadas pelo poder público. No entanto, a descentralização do poder desconcentrou os recursos apenas para a implementação e execução, mas continuou exercendo o controle dos recursos. Tudo continuou sendo previamente determinado pelo Estado, até mesmo os processos de execução. 
Estes movimentos que aconteceram e acontecem dentro e fora do Brasil serão objetos de reflexões e questionamentos neste artigo.

\section{DISCUSSÃO TEÓRICA}

\subsection{Eventos internacionais que influenciaram a educação brasileira}

Em 1990, foi produzido um documento oriundo das discussões da Conferência Mundial sobre Educação para Todos, realizada em 1990, na cidade de Jomtien, na Tailândia; a Declaração Mundial sobre Educação para Todos, que objetivava a satisfação das necessidades básicas de aprendizagem.

Segundo Souza e Kerbauy (2018), na sequência dos movimentos de renovação dos compromissos de uma "Educação Para Todos", destaca-se a Declaração de Dakar - Educação para todos, que foi resultante da Cúpula Mundial de Educação realizada em Dakar, no Senegal, que teve a finalidade de reiterar os pressupostos da Declaração Mundial sobre Educação para Todos, de Jomtien.

Em 2000, durante a Cúpula para o Milênio, foram lançados os Objetivos de Desenvolvimento do Milênio (ODM), destacamos a abrangência dos oito propostos e que foram chancelados com o apoio de 191 nações, São eles:

1 - Acabar com a fome e a miséria;

2 - Oferecer educação básica de qualidade para todos;

3 - Promover a igualdade entre os sexos e a autonomia das mulheres;

4 - Reduzir a mortalidade infantil;

5 - Melhorar a saúde das gestantes;

6 - Combater a Aids, a malária e outras doenças;

7 - Garantir qualidade de vida e respeito ao meio ambiente;

8 - Estabelecer parcerias para o desenvolvimento. 


\section{Revista \\ Debates Insubmissos}

Os Objetivos de Desenvolvimento do Milênio, foram sucedidos, em 2015, pelos Objetivos do Desenvolvimento Sustentável (ODS), propostos pela Organização das Nações Unidas (ONU), no documento Agenda 2030 (BRASIL, 2020), que é constituída por dezessete objetivos para redução da pobreza, promoção social e proteção ao meio ambiente a serem alcançados até 2030 .

A educação foi tratada nesta Conferência através do ODS 4; Objetivo de Desenvolvimento Sustentável para a educação - ODS 4.

Segundo o Fundo das Nações Unidas para a Infância (UNICEF), essa nova agenda representa uma oportunidade histórica para melhorar os direitos e o bem-estar de cada criança e cada adolescente, especialmente os mais desfavorecidos, garantir um planeta saudável para as meninas e os meninos de hoje e para as futuras gerações.

Já a Declaração de Incheon, é um documento mais recente, sendo construído em maio 2015 na Coreia do Sul. Na ocasião, foi realizado um balanço das metas de Educação para todos, relativas ao período 2000-2015, bem como, o debate e a sistematização dos princípios e diretrizes que serão definidas para os próximos quinze anos, de 2016 a 2030.

Todos os dezessete Objetivos de Desenvolvimento Sustentáveis, que compõem a Agenda 21, contribuem direta ou indiretamente para a melhoria da educação, porém o ODS 4, dirige sua ação para: Assegurar a educação inclusiva e equitativa de qualidade e promover oportunidades de aprendizagem ao longo da vida para todos.

O ODS 4 traz subitens que vão criar parâmetros e metas para os próximos 15 (quinze) anos, conforme quadro: 


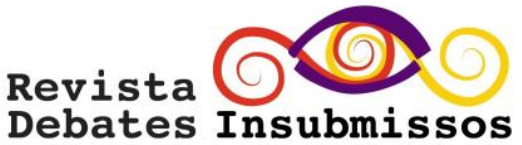

\section{SUBITENS DO OBJETIVO DE DESENVOLVIMENTO SUSTENTÁVEL}

ODS 4/AGENDA 2030.

4.1 até 2030, garantir que todas as meninas e meninos completem o ensino primário e secundário livre, equitativo e de qualidade, que conduza a resultados de aprendizagem relevantes e eficazes;

4.2 até 2030, garantir que todos os meninos e meninas tenham acesso a um desenvolvimento de qualidade na primeira infância, cuidados e educação pré-escolar, de modo que estejam prontos para o ensino primário.

4.3 até 2030, assegurar a igualdade de acesso para todos os homens e mulheres à educação técnica, profissional e superior de qualidade, a preços acessíveis, incluindo a universidade;

4.4 até 2030, aumentar substancialmente o número de jovens e adultos que tenham habilidades relevantes, inclusive competências técnicas e profissionais, para emprego, trabalho decente e empreendedorismo;

4.5 até 2030, eliminar as disparidades de gênero na educação e garantir a igualdade de acesso a todos os níveis de educação e formação profissional para os mais vulneráveis, incluindo as pessoas com deficiência, os povos indígenas e as crianças em situação de vulnerabilidade;

4.6 até 2030, garantir que todos os jovens e uma substancial proporção dos adultos, homens e mulheres, estejam alfabetizados e tenham adquirido o conhecimento básico de matemática;

4.7 até 2030, garantir que todos os alunos adquiram conhecimentos e habilidades necessárias para promover o desenvolvimento sustentável, inclusive, entre outros, por meio da educação para o desenvolvimento sustentável e estilos de vida sustentáveis, direitos humanos, igualdade de gênero, promoção de uma cultura de paz e nãoviolência, cidadania global, e valorização da diversidade cultural e da contribuição da cultura para o desenvolvimento sustentável.

4.a construir e melhorar instalações físicas para a educação, apropriadas para crianças e sensíveis às deficiências e ao gênero e que proporcionem ambientes de aprendizagem seguros, não violentos, inclusivos e eficazes para todos;

4.b até 2020 substancialmente ampliar globalmente o número de bolsas de estudo disponíveis para os países em desenvolvimento, em particular os países de menor desenvolvimento relativo, pequenos Estados insulares em desenvolvimento e os países africanos, para o ensino superior, incluindo programas de formação profissional, de tecnologia da informação e da comunicação, programas técnicos, de engenharia e científicos em países desenvolvidos e outros países em desenvolvimento;

4.c até 2030, substancialmente aumentar o contingente de professores qualificados, inclusive por meio da cooperação internacional para a formação de professores, nos países em desenvolvimento, especialmente os países de menor desenvolvimento relativo e pequenos Estados insulares em desenvolvimento.

Fonte: Elaborado pelas autoras com base no documento base da Agenda 2030 (BRASIL, 2020) 
O Estado Brasileiro, seguindo os preceitos de organismos internacionais, buscou artifícios controladores que foram caraterizados pela regulação, governança, avaliações, testes e privatizações. Segundo Fonseca (2019) o espaço europeu também, a exemplo dos espaços nacionais latino-americanos, é regulado por organismos internacionais:

Desde a década de oitenta do século XX que assistimos, claramente, no espaço europeu, as regulações/pressões, especialmente de instituições transnacionais financeiras como o Banco Mundial, o Fundo Monetário Internacional (FMI) e a Organização para a Cooperação e Desenvolvimento Econômico (OCDE), entre outras (FONSECA, 2019, p. 70).

A afirmação da autora Fonseca (2019), nos remete o quão forte é a influência destes organismos internacionais em todos os setores, mas principalmente, influenciando e moldando a Educação, segundo seus objetivos econômicos.

\subsection{O contexto atual pós-influência internacional.}

A reforma do Estado, proposta na década de 1990, vai delinear as políticas educacionais no Brasil, na medida em que propõe a avaliação externa como mecanismo de controle e regulação do Estado. Atualmente, as principais avaliações de larga escala estandardizadas, que visam apreender sobre o sistema educacional do Brasil, são o PISA (Program for Internacional Student Assessment) e o IDEB (Índice de Desenvolvimento da Educação Básica). Sendo a primeira internacional, desenvolvida pela OCDE (Organização para Cooperação e Desenvolvimento Econômico), e a segunda, nacional, desenvolvida pelo INEP (Instituto Nacional de Estudos e Pesquisa Educacionais Anísio Teixeira).

O INEP, é umas das instituições educacionais mais importantes do país, realizando, segundo as autoras Villani e Oliveira (2018), um duplo papel, desenvolvendo uma ação de nível nacional e internacional, que vai além da sua ligação com o PISA.

[...] o papel maior que o INEP realiza é de orientação da educação no país. Consequentemente, é possível afirmar que o instituto realiza um duplo papel de acordo com os três fatores anteriormente apontados: estatístico, político e geográfico. Estatístico, porque é o organismo que mais produz dados sobre a educação por meio do Censo Escolar e das diferentes avaliações da educação básica e superior. Político, porque [...], os expertos concentrados no INEP realizam orientações das estratégias das políticas educativas no país. E por fim, do ponto de vista geográfico, porque o INEP realiza um trabalho em nível nacional e internacional, não somente através do 


\section{Debates Insubmissos}

Revista

PISA, mas também com outros organismos internacionais como a UNESCO (VILLANI; OLIVEIRA, 2018, p. 1351).

O PISA é o programa de avaliação internacional mais aplicado no mundo, utiliza em suas pesquisas a TRI (Teoria de Resposta do Item), que confere uma generalização do valor preditivo dos desempenhos, sem a necessidade da aplicação da prova em sua totalidade. Analisa o conhecimento dos alunos em literacia (letramento), matemática e ciências.

O IDEB, criado em 2005 pelo INEP, é o resultado do produto entre o fluxo dos estudantes brasileiros no sistema escolar e seu desempenho, calculado por meio do SAEB (Sistema de Avaliação da Educação Básica). O IDEB, além de propositor de políticas públicas, é um indutor de ações das instituições e dos sistemas de ensino para efetivação da qualidade do atendimento. Porém, ao nosso ver, este índice é considerado um indicador de resultado, não de qualidade, mais é a partir da divulgação dos seus resultados que se pode mover ações para melhoria da qualidade no ensino.

A avaliação de larga escala é um instrumento de regulação determinado pelos objetivos educacionais a serem atingidos. O cumprimento desses objetivos é controlado através de instrumentos de avaliação que possam ser calculados quantitativamente, a exemplo do Pisa e do IDEB. A partir dos dados resultantes das avaliações, faz-se um julgamento de valor. A finalidade da avaliação como regulação se refere à classificação dos alunos em aprovados, reprovados, fracos, médios ou fortes.

Ao final do século XX, novos modelos de gestão de políticas públicas começam a ser introduzidos em escala mundial, trata-se da chamada Nova Gestão Pública, Gerencialismo e Novo Gerencialismo, este último acrescentou a democracia e a globalização ao Gerencialismo.

No Brasil, tivemos o Plano Diretor (1995), marcado por privatizações, transferências de serviços para setores públicos não estatais (terceira via) e terceirização, tendo como principal ação a transferência de serviços auxiliares e de apoio (serviços meio) para o setor privado.

Na educação isso não é diferente, os resultados das avaliações de larga escala, como o IDEB, o PDE (Plano de Desenvolvimento da Educação) e o PISA, nas mãos do gerencialismo, 
faz da educação algo mesurável, fazendo com que o Estado exerça uma política distributiva que premia ou pune, conforme maior ou menos eficiência.

Diante destas premissas, os gerencialistas criam oposições entre gestão e administração, público e privado, consumidores e cidadãos, etc.

De acordo com Clarke e Newman (2012), o Novo Gerencialismo surge para legitimar o processo de reestruturação do Estado e transforma a necessidade de mudá-lo em algo universal. Para estes autores, existem variadas formas de discurso da mudança, predominando aquele no qual está é entendida como um processo para transformação e desenvolvimento de uma "nova ordem”.

[...] pensamos que é importante reconhecer que o gerencialismo continha variantes diferentes e pensamos que duas delas eram particularmente significativas. A primeira (às vezes denominada neotaylorismo) é um pragmatismo racional de meio-fim que privilegia a eficiência e a produtividade e que favorece relações transacionais de intercâmbio e contratação. Frequentemente isto está associado a sistemas rígidas de controle, metas em cascata e rígido monitoramento de desempenho. A segunda (que se tornou conhecida na década de 1990 como novo gerencialismo) [...] é mais centrada nas pessoas e orientada para qualidade e excelência; aqui os programas de mudança de cultura procuram deixar a força de trabalho livre para inovar e aperfeiçoar os serviços e para introduzir organizações mais centradas no cliente e olhando para fora. (CLARKE; NEWMAN, 2012, p. 361).

Lima e Gandin (2017) ponderam que uma característica relevante no Novo Gerencialismo brasileiro é a dispersão de poder, além de apresentar uma lógica de mercado superior a lógica do público, maior disciplina no serviço público focando em oferecer serviços com um bom custo-benefício, enfatizando os três Es: economia, eficiência e efetividade, que foram descritos pelos autores Clarke e Newman (2012).

Gramsci (1978 apud LIMA; GANDIN, 2017) evidencia a relação de algumas condutas com a eficácia política das ideologias, há de se fazer, portanto, um esforço dialético para romper com os paradigmas excludentes que naturalizam, reforçam e ampliam as injustiças e as desigualdades sociais.

O percurso dialético é, então e sobretudo, democrático, pois não há antítese sem escuta, sem observação, sem consideração ao outro. 


\title{
Revista \\ Debates Insubmissos
}

Segundo Pena (2021), a terceirização é comum na prestação de serviços como limpeza, segurança e atendimento; pondera ainda que $25 \%$ (vinte e cinco por cento) da mão de obra no Brasil é terceirizada;

\begin{abstract}
As causas do aumento da terceirização no Brasil e no mundo têm relação com a diminuição dos custos com funcionários. Afinal, para as empresas, sai mais barato que parte de sua mão de obra seja contratada por terceiros, em vez de mantê-los sob a sua tutela, o que eleva os gastos com direitos trabalhistas e eventuais problemas de segurança do trabalho, como indenizações e outras questões. No Brasil, no entanto, existem determinadas restrições à prática da terceirização. A principal delas é a proibição da terceirização para atividades-fim, sendo permitidas apenas as atividadesmeio, ou seja, uma fábrica de doces, por exemplo, pode destinar serviços de limpeza, segurança e ordenamento para empresas terceirizadas, mas não pode fazer o mesmo para o intuito principal da empresa, que é a produção de doces industriais. Nesse caso, todos os funcionários que atuam na linha de produção devem estar legalmente vinculados à fábrica em questão, e não a uma outra empresa, com carteira assinada e todos os direitos correspondentes (PENA, 2021, s/p)
\end{abstract}

Tratando-se da terceirização dos serviços públicos federais, o Decreto n. 9.507, de 21 de setembro de 2018, revoga o Decreto n. 2.271, de 1997, e regulamenta esta prática, não fixando mais quais serviços poderiam sofrer o processo de terceirização, até então, só podiam ser objeto de terceirização, em órgãos públicos, atividades como limpeza, segurança, transportes, informática, recepção, telecomunicações e manutenção de prédios e equipamentos.

Baseando na Lei da Terceirização (Lei n. 13.429/2017), em agosto de 2018, o Supremo Tribunal Federal (STF) já havia validado, por maioria, a chamada constitucionalidade da terceirização da contratação de trabalhadores para a atividade-fim de empresas e outras pessoas jurídicas.

Para muitos pesquisadores, estes processos, que iniciaram nos anos de 1960, abrem caminho para um processo sem volta, tendo como linha de frente, os serviços da atividademeio, em que estão os trabalhadores não docentes, porém, segundo a Confederação Nacional dos Trabalhadores em Educação, outros carreiras e profissionais também estão em risco eminente ao processo de terceirização na Educação Brasileira, após estas mudanças.

Assim, as características dos tipos de atividades na Educação, atividades-fim e atividade-meio, definidos pela Confederação, podem sofrer mudanças em um espaço de tempo ainda indefinido: 


\title{
Debates Insubmissos
}

Revista

\begin{abstract}
Atividade-fim é aquela que identifica o principal objetivo de uma organização. Por exemplo, numa escola, a atividade-fim é ensinar. Isto é, os professores são os profissionais que exercem a principal função da instituição. Pela regra atual, esse tipo de atividade não pode ser delegado a terceiros, ou seja, o corpo docente precisa ser contratado pela escola [...]

Atividade-meio é aquela que não é relacionada ao objetivo final da empresa. Tomando novamente o exemplo de uma escola: a faxina e a merenda são muito importantes para o funcionamento da instituição, no entanto, não consistem nas funções primordiais da unidade. Hoje, os funcionários que exercem atividades-meio podem ser - e em muitas redes já são - contratados por empresas prestadoras de serviço (BERNARDO; SEMIS, 2017, s/p)
\end{abstract}

Para além desse argumento, existem efeitos que podem atingir a área a médio e longo prazo agora que a proposta de terceirização irrestrita, de atividades meio e fim, no setor público e privado, foi sancionada (BERNARDO; SEMIS, 2017).

\section{METODOLOGIA}

Toda pesquisa exige domínio do conhecimento científico pelo pesquisador, que resulta em ampliação do conhecimento, levando em conta os procedimentos metodológicos reconhecidos pelo meio acadêmico. A metodologia e o percurso do pesquisador e o instrumento o qual vai delinear seus estudos partir de sua criatividade e sensibilidade.

Metodologia, o caminho do pensamento e a prática exercida na abordagem da realidade, ou seja, a metodologia inclui simultaneamente a teoria da abordagem (o método), os instrumentos de operacionalização do conhecimento (as técnicas) e a criatividade do pesquisador (sua experiência, sua capacidade pessoal e sua sensibilidade) (MINAYO, 2008, p. 14).

Este artigo científico percorrerá os caminhos da análise documental e bibliográfica. Vamos a algumas reflexões sobre estes métodos e metodologias, segundo alguns autores. Sobre a utilização da pesquisa bibliográfica como metodologia de pesquisa, Oliveira (2012) afirma que a pesquisa bibliográfica proporciona a investigação de uma gama de fenômenos mais amplos do que poderia se investigar diretamente, ou seja, quando o problema da pesquisa requer a compreensão de dados dispersos no tempo e no espaço.

Através dela o pesquisador aprofunda suas reflexões sobre as considerações dos autores estudados, porém, é necessário estar atento para que não se faça apenas um resumo do material pesquisado. 


\title{
Revista \\ Debates Insubmissos
}

De acordo com Gil (2008), a pesquisa documental se aproxima muito da pesquisa bibliográfica. Sendo diferenciadas pela natureza das fontes:

\begin{abstract}
Enquanto a pesquisa bibliográfica se utiliza fundamentalmente das contribuições dos diversos autores sobre determinado assunto, a pesquisa documental vale-se de materiais que não receberam ainda um tratamento analítico, ou que ainda podem ser reelaborados de acordo com os objetivos da pesquisa. O desenvolvimento da pesquisa documental segue os mesmos passos da pesquisa bibliográfica. Apenas há que se considerar que o primeiro passo consiste na exploração das fontes documentais, que são em grande número. Existem, de um lado, os documentos de primeira mão, que não receberam qualquer tratamento analítico, tais como: documentos oficiais, reportagens de jornal, cartas, contratos, diários, filmes, fotografias, gravações etc. De outro lado, existem os documentos de segunda mão, que de alguma forma já foram analisados, tais como: relatórios de pesquisa, relatórios de empresas, tabelas estatísticas etc. (GIL, 2008, p. 51).
\end{abstract}

Gil (2008) afirma que a principal vantagem da pesquisa bibliográfica reside no fato de permitir ao investigador a cobertura de uma gama de fenômenos muito mais ampla do que aquela que poderia pesquisar diretamente. $\mathrm{O}$ autor explica ainda que a pesquisa documental é realizada a partir de análise de documentos autênticos de pessoas, instituições, organização, etc., sendo utilizada amplamente em investigações históricas, para que sejam realizadas descrições e comparações de fatos sociais ocorridos.

O autor Gil (2008), afirma que a ciência tem como objetivo fundamental chegar à veracidade dos fatos. Neste sentido, não se distingue de outras formas de conhecimento. O que torna, porém, o conhecimento científico distinto dos demais é que tem como característica fundamental a sua verificabilidade.

Para que um conhecimento possa ser considerado científico, torna-se necessário identificar as operações mentais e técnicas que possibilitam a sua verificação, em outras palavras, determinar o método que possibilitou chegar a esse conhecimento. Pode-se definir método como caminho para se chegar a determinado fim. E método científico como o conjunto de procedimentos intelectuais e técnicos adotados para se atingir o conhecimento.

Minayo (2008) também destaca a importância do pesquisador realizar questionamentos, pois eles permitem que o pesquisador ultrapasse a simples descoberta para, através da criatividade, produzir conhecimentos. Assim, para autora, o trabalho de campo deve ter ligação 


\section{Revista \\ Debates Insubmissos}

com a vontade e a identificação com o tema a ser abordado, o que permitirá ao pesquisador, uma melhor realização da pesquisa proposta.

Segundo Gil (2008) a pré-análise é a fase de organização, inicia-se, geralmente, com os primeiros contatos com os documentos (leitura flutuante). A seguir, procede-se à escolha dos documentos, à formulação de hipóteses e à preparação do material para análise.

Após realizada a leitura flutuante dos documentos pesquisados, com o objetivo de levantar hipóteses emergentes e projeção teórica da pesquisa, realiza-se o registro por meio de fichamentos, durante e depois do levantamento do material.

Segundo Marconi e Lakatos (2003), à medida que o pesquisador tem em mãos as fontes de referência, deve transcrever os dados em fichas, com o máximo de exatidão e cuidado. A ficha, sendo de fácil manipulação, permite a ordenação do assunto, ocupa pouco espaço e pode ser transportada de um lugar para outro. Até certo ponto, leva o indivíduo a pôr ordem no seu material, possibilita ainda uma seleção constante da documentação e de seu ordenamento.

Assim, ao realizarmos leituras flutuantes, tendo com parâmetros as temáticas propostas e abordadas neste artigo, utilizamos obras, artigos científicos, documentos, entre outros, que nos levam a questionamentos, reflexões e conclusões acerca das principais instituições, órgãos e organismos que influenciaram/influenciam a educação brasileira.

\section{ANÁLISE}

A educação tem sido evidenciada em vários documentos em nível nacional e internacional, tem ganhado relevância nas discussões de eventos mundiais. Akkari (2017) salienta que o debate internacional sobre o direito à educação corresponde a um movimento iniciado com o advento da globalização, em que as políticas públicas não são mais de responsabilidade exclusiva dos Estados Nações. A educação, nesse contexto, passa a ser cada vez mais objeto de crescentes influências internacionais.

Analisando sua participação desde os anos de 1990, que trazia a máxima de uma "Educação para Todos", ou seja, um período de aproximadamente 40 anos, considerando que 


\section{Revista \\ Debates Insubmissos}

a Agenda de 2030, foi pensada para atingir seus objetivos em 2030, analisando ainda as metas previstas na ODS 4 e sabendo que já se passaram 05 anos da Agenda de 2030 e da Declaração de Incheon, fazemos um alerta ao país. Temos ainda, em 2020, crianças, jovens e adultos fora da escola, nossos índices de abandono, desistências e reprovação escolares permanecem elevados. As nossas bolsas de estudos não foram ampliadas em 2020, muito pelo contrário, foram diminuídas por decreto presidencial, nossos cursos técnicos, profissionalizantes e superiores estão em redução de oferta.

Temos uma considerável taxa de analfabetismo e mais de 11 milhões de analfabetos. Segundo o IBGE (2019), a maior parte do total de analfabetos possui 15 anos ou mais, destes, $56,2 \%$ (o que corresponde a 6,2 milhões de pessoas) vivem na Região Nordeste e $21,7 \%$ (o equivalente a 2,4 milhões de pessoas) no Sudeste.

Há uma disparidade do Índice de Desenvolvimento da Educação Básica - IDEB, entre os Estados da nação brasileira. Segundo um levantamento da Revista Exame tendo como base os dados do IDEB de 2019, os estados com mais escolas de nível socioeconômico baixo tendem a ter também notas menores no IDEB (RIVEIRA, 2020).

O IDEB, passa a ranquear a educação, moldar os modelos de gestão e estabelecer critérios para liberação de recursos para as instituições, a partir de seus níveis de resultados e índices, entre outras influências.

Com a criação do IDEB em 2007, no bojo do Plano de Desenvolvimento da Educação
(PDE), como uma referência para o planejamento e orientação de políticas e
financiamento público para a educação em âmbito nacional, tem-se a consumação da
lógica econômica para a gestão e organização da educação pública. Usando os
resultados da Prova Brasil e do Sistema Nacional de Avaliação da Educação Básica
(SAEB), o IDEB passa a ter impacto direto sobre a regulação dos resultados dos
estudantes, mas também das práticas dos outros atores escolares, pois interfere nas
lógicas organizativas das escolas, incluindo seus arranjos curriculares e o
planejamento da gestão (VILLANI; OLIVEIRA, 2018, p. 1347)

Conforme os apontamentos feitos, embora tenham ocorrido avanços na educação brasileira, constatamos que o Brasil ainda precisa "fazer sua tarefa de casa", pois, assim como os alunos que aprendem e não usam seus conhecimentos para sua melhoria enquanto ser humano, não vai adiantar o país ser signatário de eventos internacionais, como tem feito a mais 


\section{Revista \\ Debates Insubmissos}

de 40 anos, assinar documentos com metas e objetivos a serem alcançados se, ao retornar para seu território não conseguir avançar na implementação destes desafios.

Conforme as análises anteriores, movidos por um objetivo comum, muitos gestores da educação e a sociedade são induzidos a participar cada vez mais deste processo, valorando mais que deveriam os resultados apresentados por estas avaliações estandardizadas, não levando em conta as fragilidades destas.

Diante deste novo modelo de gestão, muitas palavras passam a assombrar servidores de carreira docentes e não docentes, entre elas, a ameaça da terceirização dos serviços considerados atividades-meio e atividade-fim, que pode pôr a perder todas as conquistas até aqui logradas. Este termo é legítimo já que a flexibilização do trabalho aponta para a precariedade da carreira.

\section{CONCLUSÃO}

De acordo com o estudo realizado pela Revista Exame, que usou como base os dados do IDEB de 2019, os estados com escolas de nível socioeconômico baixo são aquelas que também possuem as menores notas no IDEB (RIVEIRA, 2020). Seguindo o encontrado nas análises anteriores, movidos por uma finalidade comum, muitos gestores da educação e a sociedade são induzidos a participar deste processo com mais afinco, visando apontar de forma quantitativa as ações das instituições, dando maior valor aos resultados apresentados por estas avaliações estandardizadas e não levando em conta as fragilidades encontradas nas instituições.

Existem disparidades do Índice de Desenvolvimento da Educação Básica (IDEB), entre os Estados da nação brasileira. De acordo os apontamentos realizados, mesmo tendo ocorrido avanços na educação brasileira, constata-se que o Brasil ainda precisa evoluir, pois, assim como os educandos que aprendem mas acabam não usando seus conhecimentos para se qualificar enquanto seres humanos, não adianta o país ser signatário de eventos internacionais, como tem ocorrido nos últimos 40 anos, assinar documentos com metas e objetivos a serem alcançados se, ao retornar para seu território não conseguir avançar na implementação destes desafios. 


\section{Debates Insubmissos}

Revista

A Nova Gestão Pública/Novo Gerencialismo deveria dar respostas para as tensões que surgiram após os movimentos sociais buscarem participar das decisões que eram tomadas pelo poder público, no entanto, a descentralização do poder desconcentrou os recursos apenas para a implementação e execução, mas continuou exercendo o controle dos recursos. Tudo continuou sendo previamente determinado pelo Estado, tendo os processos de execução controlados por ele.

Diante deste novo modelo de gestão, muitas palavras passam a assombrar servidores de carreira docentes e não docentes, entre elas a ameaça da terceirização dos serviços considerados atividades-meio e atividade-fim, que pode pôr a perder todas as conquistas até aqui logradas. Este termo é legítimo, já que a flexibilização do trabalho aponta para a precariedade da carreira.

O direito educativo impulsiona todos os outros direitos, por meio da garantia dos direitos ao acesso, permanência e sucesso escolar dos educandos, outros direitos básicos e fundamentais são impulsionados, inclusive atingindo a comunidade em que vive este cidadão. Os direitos mantidos e respeitados dentro do meio educacional são pulverizados para a manutenção e fortalecimento de outros direitos, tais como os direitos políticos, sociais, econômicos, entre outros, fazendo com que todos os direitos, inerentes a pessoa humana, sejam vistos e difundidos de forma abrangente e humanizada.

A vida cotidiana contemporânea reserva situações de conflitos constantes, que nos levam a mudanças e criação de novos paradigmas. Somos diferentes e como tal, pensamos, agimos, opinamos de formas diferentes. Para que possamos viver e conviver em sociedade, precisamos que nossas diferenças e conflitos sejam mediadas para que não retornemos ao estado da barbárie. Portanto, a mediação de conflitos desempenha um importante papel para que nossas construções de mundo, possam interagir de forma pacífica com outras construções de mundo diferentes.

\section{REFERÊNCIAS}

AKKARI, Abdeljalil. A agenda internacional para educação 2030: consenso "frágil" ou instrumento de mobilização dos atores da educação no século XXI. Revista Diálogo Educacional. Curitiba/PR, v. 17, n. 53, p. 937-958, 2017. 
BERNARDO, Nairim; SEMIS, Laís. 6 possíveis efeitos da terceirização na Educação: a proposta de liberar a contratação de funcionários terceirizados para qualquer tipo de atividade foi sancionada no dia 31 de março pelo presidente Michel Temer. Nova Escola, mar. 2017. Disponível em: <https://novaescola.org.br/conteudo/4865/6-possiveis-efeitos-da-terceirizacaona-educacao>. Acesso em: 04 mar. 2021.

BRASIL, Decreto n. 2.271, de 7 de julho de 1997. (Revogado pelo Decreto n. 9.507, de 2018). Dispõe sobre a contratação de serviços pela Administração Pública Federal direta, autárquica e fundacional e dá outras providências. Diário Oficial da União (DOU), Brasília/DF, jul. 1997.

BRASIL, Decreto n. 9.507, de 21 de setembro de 2018. Dispõe sobre a execução indireta, mediante contratação, de serviços da administração pública federal direta, autárquica e fundacional e das empresas públicas e das sociedades de economia mista controladas pela União. Diário Oficial da União (DOU), Brasília/DF, set. 2018. Disponível em <http://www.planalto.gov.br/ccivil_03/_Ato20152018/2018/Decreto/D9507.htm>. Acesso em: 14 jan. 2021.

BRASIL. Lei n. 13.429, de 31 de março de 2017. Dispõe sobre as relações de trabalho na empresa de prestação de serviços a terceiros. Diário Oficial da União (DOU), Brasília/DF, mar. 2017. Disponível em: <http://www.planalto.gov.br/ccivil_03/_ato20152018/2017/lei/113429.htm>. Acesso em: 01 mar. 2021.

BRASIL. Transformando Nosso Mundo: a Agenda 2030 para o Desenvolvimento Sustentável. Brasília/DF: Governo Federal, 2020. Disponível em: $<$ https://www.undp.org/content/dam/brazil/docs/agenda2030/undp-br-Agenda2030-completopt-br-2016.pdf>. Acesso em: 04 mar. 2021.

CLARKE, John; NEWMAN, Janet. Gerencialismo. Educação \& Realidade. Porto Alegre/RS, v. 37, n. 2, maio/ago. 2012.

DECLARAÇÃO de Dakar. Texto adotado pela Cúpula Mundial de Educação. Dakar/Senegal, abr. 2000. Disponível em: <http://cape.edunet.sp.gov.br/textos/declaracoes/6_Declaracao_Dakar.pdf >. Acesso em: 04 mar. 2021.

DECLARAÇÃO de Incheon. Incheon/Coreia do Sul, 2015. Disponível em: <https://media.campanha.org.br/acervo/documentos/233137POR.pdf>. Acesso em: 14 fev. 2021.

DECLARAÇÃO Universal dos Direitos Humanos. Rio de Janeiro/RJ: UNIC, 2009 [1948]. Disponível em: <http://www.dudh.org.br/wp-content/uploads/2014/12/dudh.pdf> Acesso em: 5 mar. 2021.

FONSECA, Dora Maria Ramos. O poder de regulação do discurso político-normativo: do discurso democrático ao discurso gestionário. Revista Contemporânea de Educação, Portugal, v. 14, n. 31, set/dez. 2019.

GIL, Antônio Carlos. Métodos e técnicas de pesquisa social. 6. ed. São Paulo/SP: Editora Atlas, 2008. 
IBGE. Pesquisa Nacional por Amostra de Domicílios Contínua. Diretoria de Pesquisas, Coordenação de Trabalho e Rendimento, 2019. Disponível em: $<$ https://www.ibge.gov.br/estatisticas/sociais/trabalho/9171-pesquisa-nacional-por-amostrade-domicilios-continua-mensal.html?=\&t=o-que-e>. Acesso em: 18 fev. 2021.

LIMA, Iana Gomes de; GANDIN, Luís Armando. Gerencialismo e dispersão de poder na relação Estado - educação: as traduções e os hibridismos do caso brasileiro. RBPAE - Revista Brasileira de Política e Administração da Educação. Brasília/DF, v. 33, n. 3, p. 729- 49, set./dez. 2017.

MARCONI, Marina de Andrade; LAKATOS, Eva Maria. Fundamentos de metodologia científica 1. 5. ed. São Paulo/SP: Editora Atlas 2003.

MINAYO, Maria Cecília de Souza. O desafio da pesquisa social. In: MINAYO, Maria Cecília de Souza; GOMES, Suely Ferreira Deslandes Romeu (Org.). Pesquisa social: teoria, método e criatividade. 27. ed. Petrópolis/SP: Editora Vozes, 2008, p. 9-29.

OBJETIVOS de Desenvolvimento Sustentável: ainda é possível mudar 2030. Portal do UNICEF, 2000. Disponível em: <https://www.unicef.org/brazil/objetivos-dedesenvolvimento-sustentavel>. Acesso em: 19 mar. 2021.

PENA, Rodolfo F. Alves. Terceirização e trabalho. Brasil Escola. 2021. Disponível em: <https://brasilescola.uol.com.br/geografia/terceirizacao-trabalho.htm>. Acesso em: 12 fev. 2021.

RIVEIRA, Carolina. Estados com alunos mais pobres tiveram menores notas no IDEB. Revista Exame, set. 2020. Disponível em: <https://exame.com/brasil/estados-com-alunos-maispobres-tiveram-notas-menores-no-ideb/>. Acesso em: 18 nov. 2020.

SOUZA. Kellcia Rezende; KERBAUY Maria Teresa Miceli. O direito à Educação Básica nas declarações sobre educação para todos de Jomtien, Dakar e Incheon. Revista Online de Política e Gestão Educacional. Araraquara/SP, v. 22, n. 2, maio/ago. 2018.

UNESCO. Declaração mundial sobre educação para todos. Plano de ação para satisfazer as necessidades básicas de aprendizagem. Jomtien/Tailândia, 1990.

VILLANI, Maria Luiza. OLIVEIRA, Dalila Andrade. Avaliação Nacional e Internacional no Brasil: os vínculos entre o PISA e IDEB. Revista Educação \& Realidade, Porto Alegre/RS, v. 43, n. 4, p. 1343-1362, out./dez. 2018.

Submetido: 07/03/2021

Aprovado: 01/06/2021 